\title{
Endoscopic full-thickness resection with omental patch closure for a gastric stromal tumor in the gastric cardia
}

Gastrointestinal stromal tumors (GISTs) of $\geq 2 \mathrm{~cm}$ should be resected because of their malignant potential [1]. Recently, endoscopic techniques for en bloc resection of GISTs have been described, including endoscopic submucosal dissection (ESD) and full-thickness resection

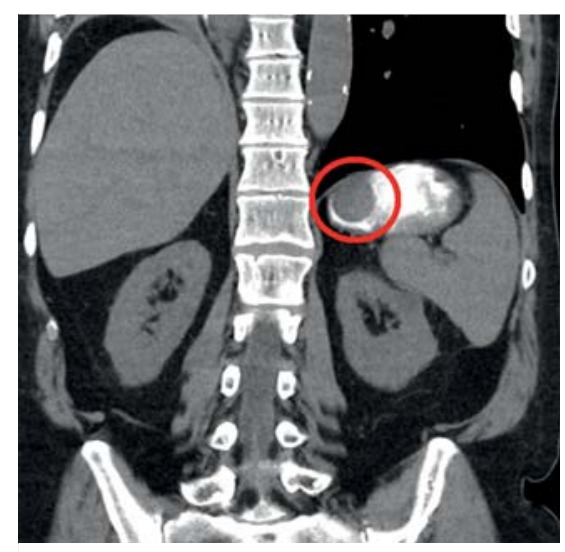

- Fig. 1 Coronal view of a computed tomography scan of the abdomen showing a mass in the gastric cardia.

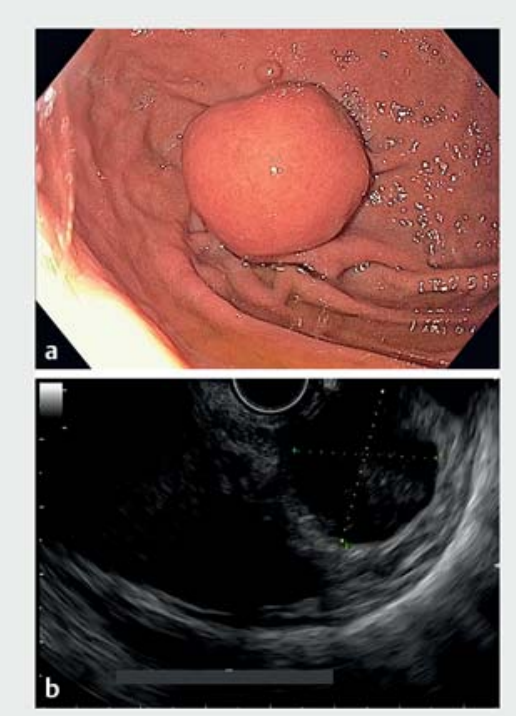

Fig. 2 The mass in the gastric cardia is seen: $\mathbf{a}$ endoscopically; $\mathbf{b}$ on endosonographic view, with the mass shown to be originating from the muscular layer.
(EFTR). Closure of the resection site, usually accomplished with clips or endoscopic suturing, is paramount to avoid peritonitis [2,3]. Prior feasibility studies have shown that omental patch closure appears to be effective for closure of gastric perforations [4,5]. Data on the use of this technique for the closure of defects after EFTR in the gastric cardia are not yet available.

We describe the case of an 82-year-old man with a gastric cardia mass found on a computed tomography (CT) scan of the abdomen (\ Fig. 1). Upper gastrointestinal endoscopy and endosonography showed a subepithelial mass arising

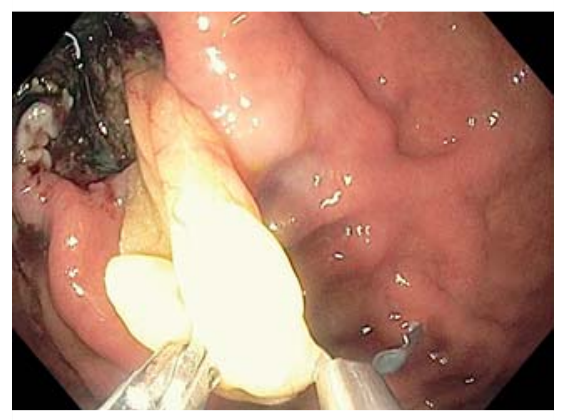

- Fig. 3 Endoscopic view showing the defect being closed using an omental patch.

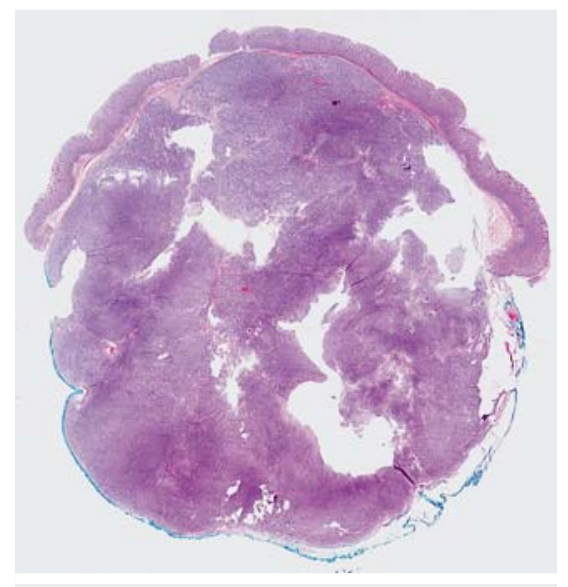

- Fig. 4 Histologic appearance showing an en bloc resection of the gastric cardia mass. from the muscularis propria ( $\triangleright$ Fig.2). Fine needle biopsy confirmed the diagnosis of a GIST.

The mass was approached in retroflexed fashion for a standard ESD technique and it was evident that part of the mass was clearly originating from the muscularis propria. The mass was then dissected off the muscularis propria, leaving approximately a $12-\mathrm{mm}$ defect in the muscularis propria and another smaller defect lateral to this. The defects could not be reliably closed with endoscopic suturing owing to their difficult location. A double-channel endoscope and forceps were used to pull omental fat through the larger muscular defect and this was patched to the gastric mucosa using multiple through-the-scope clips (Resolution; Boston Scientific, Marlborough, Massachusetts, USA) (\ Fig.3; - Video 1). The smaller muscular defect was closed using endoscopic suturing (Apollo Endosurgery, Austin, Texas, USA). Pathology showed a GIST with negative margins ( $>$ Fig.4). The patient had no adverse events and there has been no recurrence over a follow-up period of 14 months.

After en bloc EFTR of a gastric GIST in a difficult location, such as the gastric cardia, a combination of omental patch closure and endoscopic suturing is a feasible method for defect closure.

Endoscopy_UCTN_Code_CPL_1AH_2AZ

Competing interests

Mouen A. Khashab is a consultant and on the medical advisory board for Boston Scientific and Olympus America. Vivek Kumbhari is a consultant for ReShape Life Sciences, Apollo Endosurgery, Medtronic, and Boston Scientific, and receives consulting fees from Pentax Medical and C2 Therapeutics. Anthony N. Kalloo is a founding member and equity holder for Apollo Endosurgery. The other authors have nothing to declare. There is no funding support related to this submitted manuscript. 


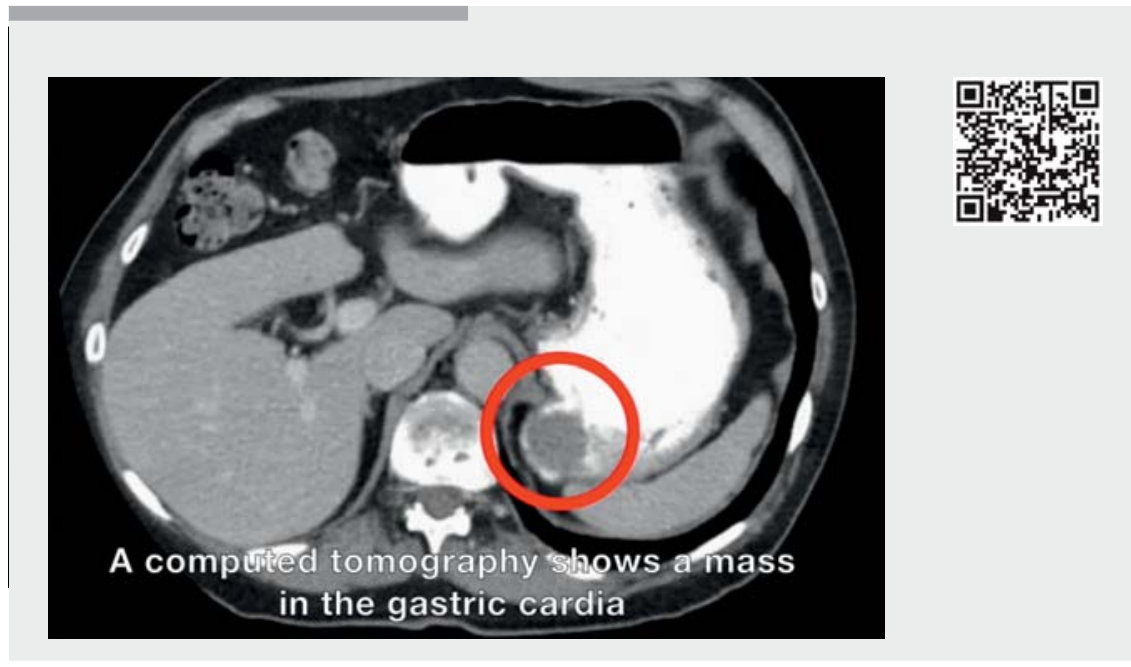

$\checkmark$ Video 1 Endoscopic full-thickness resection of a 3-cm stromal tumor in the gastric cardia, followed by a combination of endoscopic suturing and omental patch closure of the resulting defects.

The authors

\section{Tossapol Kerdsirichairat, Kia Vosoughi,} Yervant Ichkhanian, Saowanee

Ngamruengphong, Anthony N. Kalloo, Vivek Kumbhari, Mouen A. Khashab

Division of Gastroenterology and Hepatology, Department of Medicine, Johns Hopkins Medical Institutions, Baltimore, Maryland, USA

\section{Corresponding author}

Mouen A. Khashab, MD

Department of Therapeutic Endoscopy, Johns Hopkins Hospital, Shiekh Zayed Building, Division of Gastroenterology and Hepatology, 1800 Orleans Street, Suite 7125G, Baltimore, MD 21287, USA

Fax: +1-443-683-8335

mkhasha1@jhmi.edu

\section{References}

[1] Demetri GD, Benjamin RS, Blanker CD et al. NCCN Task Force report: management of patients with gastrointestinal stromal tumor (GIST) - update of the NCCN clinical practice guidelines. J Natl Compr Canc Netw 2007; 5 (Suppl. 02): S1-S29

[2] Xu M, Cai Q. Editorial: endoscopic resection of the upper gastrointestinal subepithelial tumors: promising new endoscopic techniques - are they here to stay? Am J Gastroenterol 2016; 111: 797-799

[3] Abe S, Council L, Cui X et al. Endoscopic resection and enucleation of gastric submucosal tumor facilitated by subsequent closure of incision using over-the-scope-clip. Endoscopy 2015; 47: E153 -E154

[4] Hashiba K, Carvalho AM, Diniz G Jr et al. Experimental endoscopic repair of gastric perforations with an omental patch and clips. Gastrointest Endosc 2001; 54: 500 - 504

[5] Abidi WM, Thompson CC. Endoscopic closure of an iatrogenic perforation with an omental patch. Gastrointest Endosc 2016; 83: 652

\section{Bibliography}

DOI https://doi.org/10.1055/a-0885-9031

Published online: 16.5.2019

Endoscopy 2019; 51: E278-E279

(c) Georg Thieme Verlag KG

Stuttgart · New York

ISSN 0013-726X

\section{ENDOSCOPY E-VIDEOS}

https:/|eref.thieme.de/e-videos

回局 Endoscopy E-Videos is a free access online section, reporting 自褯 on interesting cases and new techniques in gastroenterological endoscopy. All papers include a high quality video and all contributions are freely accessible online.

This section has its own submission website at https://mc.manuscriptcentral.com/e-videos 